\title{
Suicide Ideation and Attempts among Inhalant Users: Results from the National Epidemiologic Survey on Alcohol and Related Conditions
}

\author{
Matthew O. Howard, PhD, Brian E. Perron, PhD, Paul Sacco, PhD, \\ Mark Ilgen, PhD, Michael G. Vaughn, PhD, Eric Garland, MSW, \\ and Stacey Freedentahl, $\mathrm{PhD}$
}

Few studies have examined associations of inhalant use and inhalant use disorders (IUDs) to suicide ideation and attempts. We investigated these relationships in the largest comorbidity survey conducted in the United States. Suicidal ideation was significantly more prevalent among inhalant users than nonusers and severity of inhalant use problems was positively related to suicidal ideation. Among persons with IUDs, $67.4 \%$ had thought about committing suicide and $20.2 \%$ had attempted suicide. Multivariate logistic regression analyses indicated that respondents with IUDs reported significantly higher levels of suicide ideation than inhalant nonusers. Inhalant use is associated with significantly increased risk for suicide ideation, especially among women and persons with DSM-IV IUDs.

Psychiatric disorders are associated with increased risk for suicidal behavior. A psychiatric diagnosis is present in $90 \%$ or more of deaths from suicide in western countries including the United States (Bertolote, Fleischmann, De Leo, \& Wasserman, 2004). Of psy-

Matthew Howard and Eric Garland are with the University of North Carolina at Chapel Hill; Brian Perron and Mark Ilgen are with the University of Michigan at Ann Arbor; PAUL SACCO is with Washington University; MichaEl VAUGHN is with Saint Louis University; and STACEY Freedenthal is with the University of Denver.

This study was supported by grants DA021405 (Natural History, Comorbid Mental Disorders, and Consequences of Inhalant Abuse, M.O. Howard, PI), and DA15929 (Neuropsychiatric Impairment in Adolescent Inhalant Abusers, M.O. Howard, PI) from the National Institute on Drug Abuse.

Address correspondence to Dr. Matthew $O$. Howard, 325 Pittsboro, CB \#3550, The University of North Carolina at Chapel Hill, Chapel Hill, NC 27599; E-mail: mohoward@email.unc.edu chiatric disorders, substance use disorders are among the strongest known risk factors for completed suicide (Wilcox, Conner, \& Caine, 2004). According to a review of cohort studies, individuals with alcohol dependence are at 9.8 (CI: 9.0 to 10.7) times greater risk to die by suicide compared to the general population, and persons with other drug use disorders are at 13.7 (CI: 10.3 to 18.0) times greater risk (Wilcox et al., 2004). Substance use disorders are also highly predictive of suicidal thoughts, plans, and nonfatal attempts (Borges, Walters, \& Kessler, 2000; Wilcox \& Anthony, 2004). Substance use may directly induce lower serotonergic central nervous system activity and produce dysfunction in the ventral prefrontal cortex, an area responsible for inhibition of aggressive impulses (including suicide attempts). Substance use may also contribute indirectly to suicide risk via precipitation of psychosocial crises and consequent feelings of dysphoria and hopelessness (Mann, 2003). 
Relatively few studies have examined suicide risk in relation to specific psychoactive substances of abuse, but available reports suggest that inhalants may be unique in terms of the frequency and degree to which their use is associated with enhanced risk for suicide ideation and attempts-especially among girls and women (Luncheon, Bae, Gonzalez, Lurie, \& Singh, 2008; Wilcox \& Anthony, 2004). Borges et al. (2000) assessed the relationship of substance use, abuse without dependence, and dependence to risk for subsequent first suicide attempt across ten classes of psychoactive agents assessed in the $\mathrm{Na}$ tional Comorbidity Survey. Adjusted odds ratios (ORs) comparing inhalant users (OR = 1.9, CI: 1.0 to 3.5 ), inhalant abusers (OR = $10.0, \mathrm{CI}: 2.8$ to 35.0 ), and persons with inhalant dependence $(\mathrm{OR}=6.8, \mathrm{CI}: 2.4$ to 18.8$)$ to inhalant nonusers were substantial and statistically significant. Inhalant dependence was more strongly related to suicide attempts than any other type of substance dependence; similar findings were noted for inhalant abuse compared to other forms of substance abuse. Inhalant use without abuse or dependence posed a significant risk for suicide attempt but at a level similar to most other forms of substance use, suggesting that inhalant abuse and dependence may be relatively specific markers of elevated risk for suicide attempts.

In one of few longitudinal studies, Wilcox and Anthony (2004) did not find onset of alcohol or tobacco use prior to age 16 significantly associated with later risk for suicide attempt or ideation in a large sample of youth followed from first grade into young adulthood. However, onset of inhalant use prior to age 16 was a significant risk factor for suicide attempt (Relative Risk $[R R]=2.2$ ) and suicide ideation ( $R R=2.9)$ for girls, but not boys. Freedenthal et al. (2007) reported that in a sample of incarcerated adolescents, inhalant use was significantly related to suicidal ideation in girls but not boys, whereas boys and girls with formal IUDs had significantly elevated rates of suicide ideation and attempts compared to inhalant nonusers in their study of 723 antisocial adolescents. Sakai, Hall, Mikulich-Gilbertson, and Crowley
(2004) identified significantly elevated rates of lifetime suicide attempt among adolescent inhalant users with and without DSM-IV IUDs ( $32 \%$ vs. $27 \%$, respectively) compared to inhalant nonusers (15\%), but the difference between inhalant users with and without IUDs in lifetime suicide attempt prevalence was not statistically significant.

There are several possible explanations for reported findings identifying significant associations between inhalant use, IUDs and suicide ideation and attempts. Inhalation of gasoline, glue, and other neurotoxic inhalants can produce an acute intoxication syndrome similar to that produced by alcohol, including signs such as slurred speech, ataxia, and stupor or coma. Onset of intoxication occurs rapidly and may disinhibit cortical circuits regulating expression of self-injurious and other impulsive behaviors. Thus, acute inhalant intoxication may contribute to suicidal ideation and/or impulsive suicide attempts on the part of people experiencing such ideation. Persistent neurological and cognitive impairments predisposing to suicidal ideation and suicide attempts may follow repeated use of neurotoxins, such as that which occurs in IUDs. It is also possible that persons experiencing heightened levels of depression or anxiety may "self-medicate" with inhalants, which are reported by some users to have anxiolytic and euphorogenic effects (Perron, Vaughn, \& Howard, 2007). Finally, inhalant use/IUDs and suicide ideation/attempts may share common origins in factors increasing risk for both sets of conditions, including low socioeconomic status and mood, anxiety, and personality disorders. That is, the association may be noncausal and attributable to thirdfactors that increase risk for both sets of disorders.

The availability of a large, nationally representative survey incorporating assessments of inhalant use, IUDs, suicide ideation and attempts, and relevant sociodemographic covariates enabled our team to explore relationships among these variables in the largest comorbidity study conducted in the United States. Although Borges et al.'s (2000) and Sakai et al.'s (2004) results suggest that inhal- 
ant users evidence greater suicidality than inhalant nonusers, it remains unclear whether and to what extent inhalant users who progress to formal IUDs are at greater risk for suicidal ideation and attempts than inhalant users without IUDs. Thus, we hypothesized that inhalant users without IUDs would evidence significantly greater prevalence of suicide ideation and attempts than inhalant nonusers, but significantly lower prevalence of suicide ideation and attempts than adults with IUDs. That is, we expected that problematic involvement with inhalants would display a graded relationship to suicide ideation and attempts and that these relationships would be stronger in women than men.

\section{METHODS}

\section{Subjects}

Study findings are based on data from the 2001-2002 National Epidemiologic Survey on Alcohol and Related Conditions (NESARC). NESARC is a nationally representative survey of 43,093 noninstitutionalized U.S. residents aged 18 years and older (Grant, Dawson, Stinson, Chou, Kay, \& Pickering, 2003). The survey gathered information on alcohol use and comorbid conditions from individuals living in household and group settings such as shelters, college dormitories, and group homes.

NESARC utilized a multistage cluster sampling design, oversampling young adults, Hispanics, and African Americans in the interest of obtaining reliable statistical estimation in these populations, and to ensure appropriate representation of racial and ethnic subgroups, with an overall response rate of $81 \%$. Data were weighted at the individual and household level and to adjust for oversampling and nonresponse on demographic variables. Data were also adjusted to be representative (viz., region, age, race, and ethnicity) of the U.S. adult population based on the 2000 Census.

\section{Measures}

Face-to-face interviews were conducted by U.S. Census Bureau workers trained by the National Institute on Alcohol Abuse and Alcoholism. Interviewers administered the Alcohol Use Disorder and Associated Disabilities Interview Schedule-DSM-IV version (AUDADIS-IV), shown to have good reliability in assessing alcohol and drug use in the general population (Grant, Harford, Dawson, Chou, \& Pickering, 1995).

Participants in this study included lifetime inhalant nonusers and users (i.e., respondents who answered affirmatively to the question, "Have you ever used inhalants or solvents, for example, amyl nitrite, nitrous oxide, glue, toluene, or gasoline?"). An introductory statement preceding the inhalant assessment item ensured that respondents were informed that they were to report inhalants used on their own, without a doctor's prescription, and for the purposes of getting high, enjoying themselves, relaxing, feeling better, feeling more alert, quieting their nerves, or seeing how they would work. Within the sample of lifetime inhalant users, "inhalant abuse" diagnoses were assigned to respondents who met $D S M-I V$ inhalant abuse criteria only, and "inhalant dependence" diagnoses were assigned to adults who met $D S M-I V$ inhalant dependence criteria (American Psychiatric Association, 2000). In this study, respondents were classified as inhalant nonusers if they reported no lifetime inhalant use, inhalant users (IUD-) if they reported lifetime inhalant use but had never met $D S M-I V$ inhalant abuse or inhalant dependence criteria, or as inhalant users with IUDs (IUD+) if they reported inhalant use and met lifetime criteria for either inhalant abuse or dependence. Inhalant users meeting inhalant abuse or dependence criteria were combined into one group of respondents (IUD+) to maximize statistical power for group contrasts.

NESARC participants completed suicide ideation and attempt items if they responded affirmatively to one or both of two items assessing lifetime low mood and anhe- 
donia. The questions were: "In your entire life, have you ever had a time when you felt sad, blue, or down most of the time for at least 2 weeks?" and "In your entire life, have you ever had a time, lasting at least 2 weeks, when you didn't care about the things that you usually cared about, or when you didn't enjoy the things you usually enjoyed?" Overall, 13,733 (32\%) respondents reported at least one lifetime episode of low mood and/ or anhedonia; approximately $66 \%$ of those were women and the sample averaged 45.9 $(S D=17.2)$ years of age. Suicide-specific questions asked whether respondents had ever attempted suicide, thought about committing suicide, felt like they wanted to die, or thought a lot about their own death during a period of low mood. These questions were answered either "yes" or "no."

Alcohol use disorder diagnoses included lifetime alcohol abuse and alcohol dependence and were assigned in accordance with $D S M-I V$ specifications. Likewise, antisocial personality disorder, anxiety disorders (which included panic disorder, agoraphobia, social and specific phobias, and generalized anxiety disorder), mood disorders (i.e., lifetime mania, hypomania, dysthymia, and major depressive disorder), and non-inhalant drug use disorders (i.e., lifetime abuse or dependence on heroin, hallucinogens, cocaine/ crack, marijuana, stimulants, painkillers, tranquilizers, and sedatives) were also assigned consistent with DSM-IV guidelines. Race, gender, age, marital and educational status, and annual personal income were included as covariates with response categories indicated in tabled results.

\section{Analytic procedures}

Weighted prevalence estimates and $95 \%$ confidence intervals were computed using SUDAAN Version 9.0 (Research Triangle Institute, 2004). This system implements a Taylor series linearization to adjust standard errors of estimates for complex survey sampling design effects. Multivariate logistic regression analyses were conducted with simultaneous entry of covariates listed in the far left columns of tabled results. Adjusted odds ratios (AORs) and $95 \%$ confidence intervals are presented to reflect association strength and significance.

\section{RESULTS}

\section{Cbaracteristics of Inbalant Nonusers} and IUD- and IUD+ Inbalant Users

Comparisons of inhalant nonusers and IUD- and IUD+ respondents revealed significant differences across measures of gender, age, marital status, and lifetime DSM-IV diagnoses of antisocial personality disorder, anxiety disorders, mood disorders, and alcohol and non-inhalant drug use disorders (Table 1). In general, IUD-- and IUD+ users were significantly younger, more likely not to have married, and more likely to meet antisocial personality, anxiety, mood, and noninhalant substance use disorder criteria, than inhalant nonusers.

Approximately seven-in-ten IUD- respondents were male, half were between ages 18 and 34 , one third met antisocial personality disorder criteria, half evidenced a lifetime anxiety disorder, three quarters met lifetime mood disorder criteria, and more than four in five met criteria for lifetime alcohol and non-inhalant drug use disorders. IUD+ respondents tended to be disproportionately male and had significantly higher rates of lifetime antisocial personality disorder and non-inhalant drug use disorders and equivalently high rates of alcohol use disorders and mood disorders compared to IUD- respondents.

\section{Suicide Ideation and Attempts among Inbalant Nonusers and IUD- and IUD+ Respondents}

Significant group differences were identified between inhalant-nonusing, IUD-, and IUD+ respondents across all measures of suicide ideation and attempt in the total NESARC sample assessed for suicidality ( $\mathrm{Ta}-$ ble 2). Specifically, IUD- respondents re- 
TABLE 1

Cbaracteristics of NESARC Participants Completing Suicide Items, Overall and by Inbalant Use Subgroup

\begin{tabular}{|c|c|c|c|c|c|}
\hline \multirow[b]{2}{*}{ Variable } & \multirow[b]{2}{*}{$\begin{array}{c}\text { Overall } \\
N=13,733\end{array}$} & \multicolumn{4}{|c|}{ Inhalant Subgroup comparison } \\
\hline & & $\begin{array}{c}\text { Inhalant } \\
\text { Non-users } \\
N=13,356\end{array}$ & $\begin{array}{c}\text { IUD- } \\
N=287\end{array}$ & $\begin{array}{l}\text { IUD+ } \\
N=90\end{array}$ & $p \dagger$ \\
\hline \multicolumn{6}{|l|}{ Gender } \\
\hline Male & $38.09(.52)$ & $37.03(.52)$ & $69.51(3.23)$ & $75.82(5.14)$ & $.0000^{2 \mathrm{~b}}$ \\
\hline Female & $61.91(.52)$ & $62.97(.52)$ & $30.49(3.23)$ & $24.18(5.14)$ & \\
\hline \multicolumn{6}{|l|}{ Age $(\mathrm{yr})$} \\
\hline $18-34$ & $30.36(.55)$ & $29.76(.56)$ & $51.14(3.37)$ & $40.64(5.92)$ & $.0000^{\mathrm{ab}}$ \\
\hline $35-54$ & $42.87(.52)$ & $42.76(.53)$ & $43.91(3.39)$ & $54.69(5.95)$ & \\
\hline$\geq 55$ & $26.77(.52)$ & $27.48(.54)$ & $4.95(1.31)$ & $4.67(2.19)$ & \\
\hline \multicolumn{6}{|l|}{ Race } \\
\hline White & $75.66(1.24)$ & $75.47(1.26)$ & $81.88(2.93)$ & $80.77(4.43)$ & .0977 \\
\hline Non-White & $24.34(1.24)$ & $24.53(1.26)$ & $18.12(2.93)$ & $19.23(4.43)$ & \\
\hline \multicolumn{6}{|l|}{ Marital Status } \\
\hline Married/cohabitating & $56.31(.62)$ & $56.77(.64)$ & $42.19(3.58)$ & $39.90(5.85)$ & $.0000^{\mathrm{ab}}$ \\
\hline Separated/divorced/widowed & $23.21(.43)$ & $23.32(.43)$ & $18.92(2.86)$ & $22.29(4.33)$ & \\
\hline Never married & $20.48(.58)$ & $19.91(.58)$ & $38.17(3.38)$ & $37.81(5.73)$ & \\
\hline \multicolumn{6}{|l|}{ Education } \\
\hline$<$ High school & $14.69(.46)$ & $14.65(.47)$ & $14.44(2.73)$ & $21.01(5.33)$ & .7977 \\
\hline High school & $28.03(.62)$ & $28.05(.62)$ & $27.24(3.55)$ & $27.92(5.28)$ & \\
\hline$>$ High school & $57.28(.73)$ & $57.30(.74)$ & $58.32(4.16)$ & $51.08(5.90)$ & \\
\hline \multicolumn{6}{|l|}{ Personal income, $\$ / y$} \\
\hline $0-19,999$ & $25.26(.64)$ & $25.09(.64)$ & $29.51(3.27)$ & $34.42(6.38)$ & 4941 \\
\hline $20,000-34,999$ & $20.57(.49)$ & $20.57(.50)$ & $20.92(2.66)$ & $18.21(4.21)$ & \\
\hline $35,000-69,999$ & $31.45(.53)$ & $31.47(.54)$ & $32.14(3.58)$ & $26.23(6.07)$ & \\
\hline $70,000+$ & $22.73(.77)$ & $22.87(.79)$ & $17.43(2.94)$ & $21.14(5.38)$ & \\
\hline \multicolumn{6}{|l|}{ Antisocial personality disorder } \\
\hline Yes $\mathrm{r}$ (n) & $6.91(.30)$ & $5.87(.27)$ & $33.96(3.70)$ & $56.77(6.24)$ & $.0000^{\mathrm{abc}}$ \\
\hline No & $93.09(.30)$ & $94.13(.27)$ & $66.04(3.70)$ & $43.23(6.24)$ & \\
\hline \multicolumn{6}{|l|}{$\begin{array}{l}\text { Lifetime } D S M-I V \text { anxiety } \\
\text { disorder }\end{array}$} \\
\hline Yes & $34.80(.69)$ & $34.34(.69)$ & $50.01(3.67)$ & $44.63(6.33)$ & $.0003^{\mathrm{b}}$ \\
\hline No & $65.20(.69)$ & $65.66(.69)$ & $49.99(3.67)$ & $55.37(6.33)$ & \\
\hline \multicolumn{6}{|c|}{ Lifetime DSM-IV Mood Disorder } \\
\hline Yes & $61.4(.66)$ & $60.90(.67)$ & $74.77(2.96)$ & $83.83(4.25)$ & $.0000^{\mathrm{bb}}$ \\
\hline No & $38.60(.66)$ & $39.10(.67)$ & $25.23(2.96)$ & $16.17(4.25)$ & \\
\hline \multicolumn{6}{|c|}{ Lifetime $D S M-I V$ alcohol use disorder } \\
\hline Yes & $38.52(.79)$ & $36.93(.78)$ & $87.89(2.63)$ & $87.36(4.27)$ & $.0000^{\mathrm{ab}}$ \\
\hline & $61.48(.79)$ & $63.07(.78)$ & $12.11(2.63)$ & $12.64(4.27)$ & \\
\hline \multicolumn{6}{|l|}{$\begin{array}{l}\text { Lifetime } D S M-I V \text { non-inhal- } \\
\text { ant drug use disorder }\end{array}$} \\
\hline Yes & $16.44(.54)$ & $14.24(.51)$ & $81.43(2.83)$ & $94.54(2.62)$ & $.0000^{\mathrm{abc}}$ \\
\hline No & $83.56(.54)$ & $85.76(.51)$ & $18.57(2.83)$ & $5.46(2.62)$ & \\
\hline
\end{tabular}

Notes. *All Ns in column headings are unweighted values. All table values are weighted column percentages (standard errors). IUD-refers to inhalant users without lifetime $D S M$ - $I V$ inhalant abuse or dependence. IUD+ refers to inhalant users with $D S M-I V$ lifetime inhalant abuse or dependence.

†Tests of differences based on chi-square. In some cases, cell totals may not equal $100 \%$ due to rounding error. Bonferroni-corrected $p$ value $=.05 / 10=.005$.

${ }^{a}$ Pairwise post-hoc contrasts for inhalant nonusers vs. inhalant users with $D S M-I V$ inhalant use disorders (IUD+). All significant ${ }^{2}$ contrasts were significant at $p<.001$.

${ }^{b}$ Pairwise post-hoc contrasts for inhalant nonusers vs. inhalant users without $D S M-I V$ inhalant use disorders (IUD-). All significant ${ }^{b}$ contrasts were significant at $p<.001$.

'Pairwise post-hoc contrasts for inhalant users without inhalant use disorders (IUD-) vs. inhalant users with inhalant use disorders (IUD+). The contrasts for antisocial personality disorder and noninhalant drug use disorders were significant at $p<.01$. 
TABLE 2

Proportions of NESARC Respondents with a History of Suicide Attempts and Ideation, Overall and by Inbalant Use Subgroups

\begin{tabular}{|c|c|c|c|c|c|}
\hline \multirow[b]{2}{*}{ Suicide variable } & \multirow[b]{2}{*}{$\begin{array}{c}\text { Overall } \\
N=13,552 \\
\end{array}$} & \multicolumn{4}{|c|}{ Inhalant User Subgroup Comparisons } \\
\hline & & $\begin{array}{c}\text { Inhalant Non-users } \\
\text { Total, } N=13,180 \\
\text { Males, } n=4,379 \\
\text { Females, } n=8,801\end{array}$ & $\begin{array}{c}\text { IUD- } \\
\text { Total, } N=284 \\
\text { Males, } n=185 \\
\text { Females, } n=99\end{array}$ & $\begin{array}{c}\text { IUD+ } \\
\text { Total, } N=88 \\
\text { Males, } n=63 \\
\text { Females, } n=25 \\
\end{array}$ & $p^{\dagger}$ \\
\hline \multicolumn{6}{|l|}{ Suicide attempt } \\
\hline Total & $7.48(.28)$ & $7.12(.27)$ & $18.02(2.78)$ & $20.15 \quad(4.46)$ & $.0002^{2, b}$ \\
\hline Males & $6.49(.46)$ & $5.78(.43)$ & $18.08(3.53)$ & $16.73(5.03)$ & $.0017^{2, b}$ \\
\hline Females & $8.08(.33)$ & $7.90(.33)$ & $17.87(4.48)$ & $30.85(10.41)$ & $.0198^{\mathrm{a}, \mathrm{b}}$ \\
\hline \multicolumn{6}{|c|}{$\begin{array}{l}\text { Thought about } \\
\text { committing suicide }\end{array}$} \\
\hline Total & $26.38(.64)$ & $25.68(.62)$ & $50.84(3.78)$ & $67.42 \quad(6.17)$ & $.0000^{a, b, c}$ \\
\hline Males & $26.31(.88)$ & $24.81(.87)$ & $48.82(4.54)$ & $65.25 \quad(7.19)$ & $.0000^{2, b}$ \\
\hline Females & $26.43(.71)$ & $26.19(.70)$ & $55.43(5.79)$ & $74.21(10.02)$ & $.0001^{a, b}$ \\
\hline \multicolumn{6}{|c|}{$\begin{array}{l}\text { Felt like you wanted } \\
\text { to die }\end{array}$} \\
\hline Total & $32.35(.60)$ & $31.69(.59)$ & $52.70(3.72)$ & $66.90 \quad(5.45)$ & $.0000^{a, b, c}$ \\
\hline Males & $29.35(.84)$ & $27.87(.83)$ & $51.05(4.48)$ & $63.66(6.91)$ & $.0000^{\mathrm{a}, \mathrm{b}}$ \\
\hline Females & $34.19(.74)$ & $33.93(.73)$ & $56.52(5.66)$ & $77.01 \quad(9.21)$ & $.0003^{\mathrm{a}, \mathrm{b}}$ \\
\hline \multicolumn{6}{|c|}{$\begin{array}{l}\text { Thought a lot about } \\
\text { your own death }\end{array}$} \\
\hline Total & $25.41(.48)$ & $24.92(.47)$ & $37.22(3.27)$ & $55.13 \quad(6.49)$ & $.0000^{a, b, c}$ \\
\hline Males & $25.69(.74)$ & $24.90(.75)$ & $33.26(3.94)$ & $58.39 \quad(7.53)$ & $.0009^{a, b, c}$ \\
\hline Females & $25.24(.59)$ & $24.93(.58)$ & $46.24(5.39)$ & $44.95(12.07)$ & $.0011^{b}$ \\
\hline
\end{tabular}

Notes. All Ns in column headings are unweighted values. Table values are weighted column percentages (standard errors). IUD- refers to lifetime inhalant users without lifetime DSM-IV inhalant abuse or dependence. IUD+ refers to inhalant users with $D S M-I V$ lifetime inhalant abuse or dependence.

$\dagger$ Tests of differences based on $\chi^{2}$. The Bonferroni-adjusted $p$ value was $.05 / 12=.004$.

${ }^{2}$ Pairwise post-hoc contrasts for inhalant nonusers vs. inhalant users with $D S M-I V$ inhalant use disorders (IUD+). For total sample, all ${ }^{2}$ contrasts were significant at $p<.001$, except suicide attempt ( $p$ $<.01$ ). For males, thought about committing suicide and felt like you wanted to die were significant at $p<.001$, thought a lot about your own death at $p<.01$, and suicide attempt at $p<.05$. For females, thought about committing suicide and felt like you wanted to die were significant at $p<.01$, and suicide attempt was significant at $p<.05$.

${ }^{b}$ Pairwise post-hoc contrasts for inhalant nonusers vs. inhalant users without DSM-IV inhalant use disorders (IUD-). All such contrasts for the total sample were significant at $p<.001$. For men, thought about committing suicide and felt like you wanted to die were significant at $p<.001$, suicide attempt at $p<.01$, and thought a lot about your own death at $p<.05$. For females, thought about committing suicide and thought a lot about your own death were significant at $p<.001$, felt like you wanted to die at $p<.01$, and suicide attempt at $p<.05$.

'Pairwise post-hoc contrasts for inhalant users without inhalant use disorders (IUD-) vs. inhalant users with inhalant use disorders (IUD+). All significant ${ }^{c}$ contrasts for the total sample were significant at $p<.05$. For males, thought a lot about your own death was significant at $p=.01$. For females, no post hoc contrasts were statistically significant; $p$ values ranged from .10 to .22 for the variables in the first three rows of Table 2, suggesting that low statistical power may have been a factor in the failure to detect significant IUD - vs. IUD+ in women across measure of suicide despite apparently moderate-tolarge effects. 
ported significantly higher lifetime prevalence rates of thinking about suicide, feeling like they wanted to die, and thinking a lot about their own death than inhalant nonusers, but significantly lower rates of suicide ideation compared to IUD+ respondents. The prevalence of suicide ideation was very high $(55 \%-67 \%)$ for IUD+ respondents across all three measures. IUD+ women reported higher rates of thinking about committing suicide and feeling like they wanted to die than IUD+ men, whereas IUD+ men were more likely to report thinking a lot about their own death than IUD+ women.

IUD- and IUD+ respondents exhibited significantly elevated rates of one or more lifetime suicide attempts compared to inhalant nonusers, although differences between IUD- and IUD+ respondents were not substantial overall or for men. Nearly one-in-three IUD+ women reported a lifetime suicide attempt compared to fewer than one-in-five IUD- women and one-in-thirteen women who were inhalant nonusers, although these differences did not attain statistical significance due to low power. Thus, for all three measures of suicide ideation among women, there was bivariate evidence of an monotonic association between extent of problematic involvement with inhalants and suicidal thoughts. Inhalant users evidenced significantly higher rates of suicide attempts than did nonusers.

\section{Multivariate Logistic Regression Prediction of Suicide Ideation and Attempts}

Multivariate logistic regression was used to examine associations between inhalant use and each suicide ideation and attempt measure, while adjusting for other sociodemographic and clinical variables. The results indicated that IUD+ but not IUD- respondents were significantly more likely to report suicidal ideation compared to inhalant nonusers. Neither IUD- or IUD+ respondents exhibited a significantly higher likelihood of reporting actual suicide attempts compared to inhalant nonusers.
Other factors associated with suicide ideation and attempts included being female; younger; separated; divorced, or widowed; currently married or cohabitating (inversely associated); having lower annual incomes and less education, and having met criteria for antisocial personality, anxiety, mood, alcohol use, and non-inhalant drug use disorders. It is notable that even with the effects of a significant number of psychiatric, substancerelated, and sociodemographic variables controlled for, IUD+ adults were at significantly elevated risk for suicidal ideation.

Odds ratios reflecting comparisons of IUD- to IUD+ inhalant users across measures of lifetime suicide attempt, thinking about committing suicide, feeling like you wanted to die, and thinking about your own death were not significant (Table 3; analyses available upon request).

\section{DISCUSSION}

Study findings provide partial support for a positive association between severity of problematic inhalant involvement and suicidality. In bivariate analyses, prevalence of suicide ideation in inhalant users without IUDs was much higher than that reported by inhalant nonusers, but lower than the prevalence of suicide ideation reported by adults with IUDs. Multivariate logistic regression analyses, controlling for psychiatric, substance-related, and sociodemographic factors, indicated that IUD+ respondents had substantially greater odds of reporting suicidal ideation than inhalant nonusers.

Bivariate analyses revealed a significantly greater prevalence of lifetime suicide attempts among IUD- respondents compared to inhalant nonusers and indicated that that IUD- men and women reported similar proportions with lifetime suicide attempts, but IUD+ women reported nearly twice the prevalence of suicide attempts as IUD+ men (and IUD- men and women). In multivariate logistic regression analyses, women were significantly more likely then men to attempt suicide but no significant main effects on sui- 
TABLE 3

Adjusted Odds Ratios Reflecting Associations Between Inbalant Use and Suicide Attempts and Ideation Among NESARC Respondents Completing Suicide Attempt and Ideation Items, $\mathrm{N}=13,552$

\begin{tabular}{|c|c|c|c|c|}
\hline $\begin{array}{l}\text { Independent } \\
\text { Variables }\end{array}$ & $\begin{array}{c}\text { Suicide } \\
\text { attempt } \\
\text { AOR }(95 \% \mathrm{CI})\end{array}$ & $\begin{array}{l}\text { Think about } \\
\text { committing suicide } \\
\text { AOR }(95 \% \mathrm{CI})\end{array}$ & $\begin{array}{l}\text { Feel like wanted } \\
\text { to die } \\
\text { AOR }(95 \% \mathrm{CI})\end{array}$ & $\begin{array}{l}\text { Think about } \\
\text { own death } \\
\text { AOR ( } 95 \% \text { CI) }\end{array}$ \\
\hline \multicolumn{5}{|l|}{ Inhalant group } \\
\hline IUD- & $1.23(.80-1.90)$ & $1.40 \quad(.96-2.05)$ & $1.38(.96-1.99)$ & $.93(.67-1.30)$ \\
\hline IUD+ & $1.09(.58-2.06)$ & $2.19(1.18-4$ & $1.99(1.18$ & $1.62(.91-2.86)$ \\
\hline \multicolumn{5}{|l|}{ Sex } \\
\hline $\begin{array}{l}\text { Female } \dagger \\
\text { Male }\end{array}$ & $.67(\overline{55}-.81)$ & $.90(\overline{81-1.01)}$ & $.76 \overline{(.69-.85)}$ & $1.01(. \overline{91}-1.14)$ \\
\hline \multicolumn{5}{|l|}{ Age (yr) } \\
\hline $\begin{array}{l}18-34 \dagger \\
35-54 \\
\geq 55\end{array}$ & $\begin{array}{l}.77(.62-.95) \\
.47(.36-.62)\end{array}$ & $\begin{array}{l}.89(. \overline{77}-1.02) \\
.73(.62-.87)\end{array}$ & $\begin{array}{l}.95(.84-1.08) \\
.85(.72-1.0)\end{array}$ & $\begin{array}{l}.87(. \overline{77}-.99) \\
.80(.69-.92)\end{array}$ \\
\hline \multicolumn{5}{|l|}{ Race } \\
\hline White & - & - & - & - \\
\hline Non-White & $1.18(.99-1.41)$ & $.89(.78-1.01)$ & $1.05(.93-1.17)$ & $1.22(1.09-1.36)$ \\
\hline \multicolumn{5}{|l|}{ Marital status } \\
\hline $\begin{array}{l}\text { Married/cohabitating } \\
\text { Senarated/divorced/ }\end{array}$ & $.91 \quad(.72-1.15)$ & $.81(.71-.93)$ & $.86(.75-.98)$ & $.79(.70-.90)$ \\
\hline & $1.43(1.13-1.80)$ & $1.02(.86-1.22)$ & $1.07(.91-1.26)$ & $.89(.77-1.02)$ \\
\hline \multicolumn{5}{|l|}{$\begin{array}{l}\text { Education } \\
>\text { High schoolt }\end{array}$} \\
\hline Hig. & $1.09 \quad(.90-1.32)$ & $.91(.81-1.03)$ & $1.13(1.01-1.26)$ & $1.00(.89-1.13)$ \\
\hline$<$ High school & $38(1.08-1.77)$ & $.94(.81-1$ & $1.20(1.03-1.39)$ & $1.11(.95-1.31)$ \\
\hline \multicolumn{5}{|l|}{ Personal income, $\$ / y$} \\
\hline $0-19,999 \dagger$ & $-\overline{-1}$ & $\overline{-}$ & - & - \\
\hline $\begin{array}{l}20,000-34,999 \\
35,000-69,999\end{array}$ & $\begin{array}{l}.75(.60-.92) \\
.63(.51-.79)\end{array}$ & $.88(.76-1.02)$ & $.88(.76-1.02)$ & $\begin{array}{l}.94(.82-1.08) \\
.86(.75-.99)\end{array}$ \\
\hline $\begin{array}{l}35,000-69,999 \\
70,000+\end{array}$ & $.51(.37-.70)$ & $.72(.61-.86)$ & $.71(.60-.85)$ & $.87(.72-1.05)$ \\
\hline \multicolumn{5}{|l|}{$\begin{array}{l}\text { Antisocial personality } \\
\text { disorder }\end{array}$} \\
\hline Not & - & - & - & - \\
\hline Yes & $2.32(1.83-2.96)$ & $2.02(1.62-2.52)$ & $1.58(1.31-1.91)$ & $1.72(1.39-2.13)$ \\
\hline \multicolumn{5}{|l|}{ Lifetime anxiety disorder } \\
\hline Yes & $1.41(1.18-1.69)$ & $1.39(1.25-1.54)$ & $1.45(1.32-1.59)$ & $1.49(1.35-1.65)$ \\
\hline \multicolumn{5}{|l|}{$\begin{array}{l}\text { Lifetime alcohol use } \\
\text { disorder }\end{array}$} \\
\hline Not & - & - & - & - \\
\hline $\begin{array}{l}\text { Yes } \\
\text { Lifetime mood disorder }\end{array}$ & $1.30(1.07-1.58)$ & $1.31(1.16-1.48)$ & $1.23(1.10-1.37)$ & $\mathbf{1 . 1 8}(1.05-1.33)$ \\
\hline $\begin{array}{l}\text { Lifetime mood disorder } \\
\text { No† }\end{array}$ & - & - & & \\
\hline Yes & $5.43(4.11-7.19)$ & $6.15(5.33-7.09)$ & $7.22(6.32-8.25)$ & $4.15(3.63-4.74)$ \\
\hline $\begin{array}{l}\text { Lifetime non-inhalant drug } \\
\text { use disorder }\end{array}$ & & & & \\
\hline Not & - & - & - & - \\
\hline Yes & $1.56(1.26-1.93)$ & $1.51(1.32-1.72)$ & $1.41(1.23-1.62)$ & $1.26(1.08-1.47)$ \\
\hline
\end{tabular}

Notes. Values in bold are significant based on a $95 \%$ confidence interval that does not bound 1.0. All reported odds ratios were adjusted for the remaining variables listed in the far left column of the table.

AOR $=$ Adjusted odds ratio.

IUD- refers to lifetime inhalant users without lifetime $D S M-I V$ inhalant abuse or dependence.

IUD+ refers to lifetime inhalant users with $D S M-I V$ lifetime inhalant abuse or dependence.

$\dagger=$ reference group. 
cide attempts were observed for status as a IUD- or IUD+ inhalant user relative to inhalant nonuser. As noted above, post boc multiple logistic regression follow-up analyses testing gender times inhalant-user-category interaction terms across lifetime suicide attempts were nonsignificant.

Thus, our findings support a significant relationship between inhalant use, IUDs, and suicide ideation, but provide less clear findings with respect to suicide attempts. IUDand IUD+ adults had lifetime suicide attempt prevalence rates nearly three times greater than inhalant nonusers in bivariate analyes, but inhalant use and IUDs were not related to suicide attempt in multivariate analyses. It is possible that the null findings for inhalant use and suicide attempts in multivariate analyses were due to the statistical procedures employed, which controlled comprehensively for the effects of psychiatric comorbidities commonly associated with suicide and occurring disproportionately in IUD- and IUD+ adults compared to inhalant nonusers ADDIN \{ ADDIN EN.CITE.DATA (Wu \& Howard, 2007; Wu, Howard, \& Pilowsky, 2008). Another possibility is that IUD- and especially IUD+ individuals tend to use more lethal means for attempting suicide than non-inhalant users and were therefore not included in the NESARC survey if they completed suicide. Testing this hypothesis would require data on completed suicides among nonusers and IUD- and IUD+ individuals, which are currently unavailable.

The causal role of inhalant use and IUDs in suicide attempts remains unclear and continued study of these associations is clearly needed. Further, Borges et al. (2000) reported disaggregated findings which suggested that the effects of substance use may primarily be on suicide ideation and unplanned suicide attempts, rather than on planned attempts. Mann (2003) has noted the role that substance-related neurotoxicity, particularly in the ventral prefrontal cortex, may play in disinhibiting aggressive behavior and promoting impulsive acts such as suicide attempts. Thus, greater specificity would be desirable in the assessment of specific forms of suicidal behavior, particularly suicide attempts.

Particularly striking in the current study were the findings that nearly one-inthree IUD+ women had attempted suicide and that more than half of IUD-- and three quarters of IUD+ women had thought about committing suicide and felt like they wanted to die, respectively. These results are compatible with contemporary reports indicating that girls and women who use inhalants and/ or develop IUDs are at elevated risk for suicidal thoughts and attempts. For example, Luncheon et al. (2008) found high rates of inhalant use in adolescent females contemplating suicide and an odds ratio of 2.6 for suicidal thoughts among adolescent females who had versus had not used inhalants. The investigations of Freedenthal, Vaughn, Jenson, and Howard (2007) and Wilcox and Anthony (2004) provide further indication that inhalant use in females may be more strongly associated with suicidality than in males.

Possible reasons for a significant association of inhalant use to suicidality among girls and women are that inhalant use in females may reflect a comparatively more psychiatrically troubled or antisocial profile relative to such use in male inhalant users; may be attributable to self-medication with inhalants of anxious and depressive mood states that are observed more frequently in females than males (Perron et al., 2007); or that inhalant use may disinhibit suicide ideation and attempts in girls and women with low mood, dysthymia, and major depressive disorder, which they experience at disproportionately high levels (Howard, Balster, Cottler, $\mathrm{Wu}, \&$ Vaughn, 2008; Wu et al., 2008). At a minimum, the findings suggest that treatment and prevention resources should be targeted to girls and women using inhalants.

With regard to general profiles, it is notable that among persons with a history of low mood, IUD+ adults tend to be comparatively young, unmarried, antisocial, and afflicted with high rates of anxiety, mood, alcohol, and non-inhalant drug use disorders compared to inhalant nonusers. While IUD+ women evidenced high levels of suicide at- 
tempt and ideation, it is also true that nearly two thirds of IUD+ men report having thought about committing suicide and feeling like they wanted to die. The high risk profile that characterizes IUD+ adults (and IUD- adults to a lesser though still significant degree) has been reported in other investigations of youth and adult inhalant users (Howard et al., 2008; Wu \& Howard, 2007; Wu et al., 2008).

This research is characterized by several limitations. Although data were collected via a structured psychiatric interview using a psychometrically sound instrument, they are based on self-report and subject to typical limitations of self-report data including unreliable retrospective recall. Further, crosssectional studies cannot establish causality. Thus, the etiological nature of the relationship among inhalant use, IUDs, and suicidality cannot be determined in the present study.

\section{REFERENCES}

American Psychiatric Association. (2000). Diagnostic and statistical manual of mental disorders (4th ed.). Washington, DC: Author.

Bertolote, J. M., Fleischmann, A., De Leo, D., \& Wasserman, D. (2004). Psychiatric diagnoses and suicide: Revisiting the evidence. Crisis, 25, 147-155.

Borges, G., Walters, E. E., \& Kessler, R. C. (2000). Associations of substance use, abuse, and dependence with subsequent suicidal behavior. American 7ournal of Epidemiology, 151, 781-789.

Botnick, M. R., Heath, K. V., Cornelisse, P. G., Strathdee, S. A., Martindale, S. L., \& Hogg, R. S. (2002). Correlates of suicide attempts in an open cohort of young men who have sex with men. Canadian Fournal of Public Health, 93, 59-62.

Freedenthal, S., Vaughn, M. G., Jenson, J. M., \& Howard, M. O. (2007). Inhalant use and suicidality among incarcerated youth. Drug and Alcobol Dependence, 90, 81-88.

Grant, B. F., Dawson, D. A., Stinson, F. S., Chou, P. S., Kay, W., \& Pickering, R. (2003). The Alcohol Use Disorder and Associated Disabilities Interview Schedule-IV (AUDADISIV): Reliability of alcohol consumption, tobacco use, family history of depression and psychiatric diagnostic modules in a general population sample. Drug and Alcobol Dependence, 71, 7-16.

Grant, B. F., Harford, T. C., Dawson,
Future investigations should include more extensive assessments of use and abuse/ dependence on specific inhalant products and should focus on pathogenetic processes that contribute to findings of significant associations between suicidality and inhalant use, particularly among girls and women. Findings of this report are consistent with recent studies suggesting that inhalant use is associated with completed suicide (Wick, Gilbert, Felgate, \& Byard, 2007) and suicide attempts in populations ranging from schizophrenics (Shoval et al., 2006) to homeless and runaway youth (Greene \& Ringwalt, 1996) to men who have sex with men (Botnick, Heath, Cornelisse, Strathdee, Martindale, \& Hogg, 2002). Far more research is needed to address the potential role that inhalant use and IUDs, which are prevalent in many nations, may play in suicidal ideation, suicide attempts, and completed suicides.

D. A., Chou, P. S., \& Pickering, R. P. (1995). The Alcohol Use Disorder and Associated Disabilities Interview Schedule (AUDADIS): Reliability of alcohol and drug modules in a general population sample. Drug and Alcobol Dependence, 39, $37-44$.

GreENe, J. M., \& Ringwalt, C. L. (1996). Youth and familial substance use's association with suicide attempts among runaway and homeless youth. Substance Use \& Misuse, 31, 1041-1058.

Howard, M. O., Balster, R. L., Cottler, L. B., WU, L.-T., \& VAUGHN, M. G. (2008). Inhalant use among incarcerated adolescents in the United States: Prevalence, characteristics, and correlates of use. Drug and Alcobol Dependence, 93, 197-209.

Luncheon, C., Bae, S., Gonzalez, A., LuRIE, S., \& Singh, K. P. (2008). Hispanic female adolescents' use of illicit drugs and the risk of suicidal thoughts. American fournal of Health Bebavior, 32, 52-59.

ManN, J. J. (2003). Neurobiology of suicidal behavior. Nature Reviewss, 4, 819-828.

Perron, B. E., Vaughn, M. G., \& HowARD, M. O. (2008). Reasons for using inhalants: Evidence for discrete classes in a sample of incarcerated adolescents. Fournal of Substance Abuse Treatment, 34(4), 450-455.

SakaI, J. T., Hall, S. K., MikulichGilbertson, S. K., \& Crowley, T. J. (2004). In- 
halant use, abuse, and dependence among adolescent patients: Commonly comorbid problems. Journal of the American Academy of Child and Adolescent Psychiatry, 43, 1080-1088.

Shoval, G., Sever, J., Sher, L., Diller, R., Apter, A., Weizman, A., et al. (2006). Substance use, suicidality, and adolescent-onset schizophrenia: An Israeli 10-year retrospective study. Fournal of Child and Adolescent Psychopharmacology, 16, 767775 .

Wick, R., Gilbert, J. D., Felgate, P., \& Byard, R. W. (2007). Inhalant deaths in South Australia: A 20-year retrospective autopsy study. American fournal of Forensic Medicine and Patbology, 28, 319-322.

Wilcox, H. C., \& Anthony, J. C. (2004). The development of suicide ideation and attempts: An epidemiologic study of first graders followed into young adulthood. Drug and Alcobol Dependence, 76 (suppl.) S53-S67.
Wilcox, H. C., Conner, K. R., \& Caine, E. D. (2004). Association of alcohol and drug use disorders and completed suicide: An empirical review of cohort studies. Drug and Alcobol Dependence, 76 (suppl.) S11-S19.

Wu, L.-T., \& Howard, M. O. (2007). Psychiatric disorders in inhalant users: Results from the National Epidemiologic Survey on Alcohol and Related Conditions. Drug and Alcobol Dependence, 88, 146-155.

Wu, L. T., Howard, M. O., \& Pilowsky, D. J. (2008). Substance use disorders among inhalant users: Results from the National Epidemiologic Survey on Alcohol and Related Conditions. Addictive Bebaviors, 33, 968-973.

Manuscript Received: June 7, 2009 Revision Accepted: June 7, 2009 